\title{
A Simple Predictive Performance Model of Solar Cell under Very Hot and Humide Climate
}

\author{
Mougang Yolande Christelle Ketchanji*, Essiane Salomé Ndjakomo, Imano Adolphe Moukengue \\ Laboratory Technology and Applied Sciences, University of Douala, Douala, Cameroon \\ Email: *ketchanji202000@yahoo.fr
}

How to cite this paper: Ketchanji, M.Y.C., Ndjakomo, E.S. and Moukengue, I.A. (2019) A Simple Predictive Performance Model of Solar Cell under Very Hot and Humide Climate. Journal of Power and Energy Engineering, 7, 26-47.

https://doi.org/10.4236/jpee.2019.75004

Received: April 26, 2019

Accepted: May 24, 2019

Published: May 27, 2019

Copyright $\odot 2019$ by author(s) and Scientific Research Publishing Inc. This work is licensed under the Creative Commons Attribution International License (CC BY 4.0).

http://creativecommons.org/licenses/by/4.0/

\begin{abstract}
In the scope of solar energy-based electrical needs in rural tropical regions, the present article develops and confronts experimental power models from the using of manufacturer data and a new model made with the meteorological and electrical data acquired. These data are registered through an acquisition station around a monocrystalline photovoltaic panel, designed and realized in the scope of this work. After the acquisition of meteorological data, a choice of the most relevant meteorological variable as input vectors to express the output powers obtained was carried out. Around the Single-Diode model, seven models are performed with analytics equations, iterative methods and an optimization method with a multi-objective function to get internal parameters. The proposed experimental model is made by a combination of the solution got at STC of an iterative method, with the value of nameplate and the use of an open circuit voltage equation with experimental coefficient to predict power output in operating conditions, and it's demonstrated more efficient. The optimization of a multi-objective function using Nonlinear Squares (NLS) through the Leveng-Marqued method to solve the parameter estimation of a PV panel has been well done and the results are useful, like classic iterative method and less time-consuming.
\end{abstract}

\section{Keywords}

Experimental, Modelling, Maximal Power Output (MPO), Photovoltaic (PV), $1 \mathrm{M} 5 \mathrm{P}$

\section{Introduction}

Around $84 \%$ of 1.5 billion people without electricity access reside in rural areas and more than $95 \%$ of those living without electricity are in countries in sub-Saharan Africa and developing Asia [1]. In rural areas, more than 1.5 billion people lack 
access to electricity scattered settlements, and hard-to-reach areas. Especially in Cameroon where only $21.7 \%$ of rural areas were electrified in 2016 , due to a fragile economy, costly infrastructure, disseminated habitation and impassable roads. However, the balance of primary energy sources shows a huge dominance of renewable energies: The available hydraulic power is $13.7 \mathrm{GW}$, and the average irradiance is $4.9 \mathrm{kWh} / \mathrm{day} / \mathrm{m}^{2}$ in the case of Cameroon [2]. Thus, to decentralize the electrical production and use renewable energies considering their seasonal availability is a huge and urgent challenge. To answer it, a good and realistic modelling of constitutive elements of a power plant is primordial. The aim of this work is to build a robust model to predict electrical power behavior along a day from experimental data for the most present PV module on the rural market. Another scope is to fill the lack of important electrical value for modelling of a solar panel, not provided by manufacturer like I-V and P-V curves on their datasheet, or not accurate like temperature coefficients, because the usual market panels are not tested under tropical climate conditions. This work leads to evaluate in opposition to usual literature models, the real efficiency of the PV module under meteorological conditions of an equatorial tropical climate.

In this perspective, this work deals with the acquisition of meteorological data and their impact on power output module. Then the confrontation of different mathematical single diode models with manufacturer's parameters, through models with experimental data from the monocrystalline silicon module LW-MS50 will be performed. Finally, a comparison of different power output pattern based on meteorological data is highlighted.

\section{State of Art}

The future of the photovoltaic industry is encouraged as the efficiency of the cell and submodules continues to increase [3]. However, the design and optimization of the photovoltaic system is a difficult step because of the influence of weather conditions on the characteristics and performance of the PV module [4].

Several studies have been done on the variation in efficiency using different PV technologies [5] [6]. It turns out that the meteorological factors individually influence the models and the performance of all components of the PV module.

Also, the literature review presents some basic knowledge about the modeling PV modules [7] [8]. Models using constant parameters have been proposed [9] but these models are inaccurate because they don't take into account the temperature variation. In this decade, we develop unique exponential models that neglect shunt resistance [10] [11]. Also, the researchers proposed models considering the temperature and irradiance proposed in the technical sheet [12].

However, despite the existence of numerous mathematical models and software applications for photovoltaics, sizing is only suitable for the non-tropical regions where they are built [13].

Given the existence of several power models [13] [14] [15], and their varia- 
tions according to the meteorological conditions, this work after presented the acquisition station, underline in first, the main factors of power variation, then the estimate of this power through mathematical modeling combining various literature approaches for obtaining I-V and $\mathrm{P}-\mathrm{V}$ characteristics and finally a comparison of power output models with ours and experimental data will be performed.

\section{Principle, Data Acquisition and Variations}

\subsection{Acquisition Station}

Few works compare different PV panels or different algorithms at real operating conditions with simulations, or only with experimental evaluation, because it is difficult to find or wait for the same environmental conditions during the experimental tests. Very high costs and feasibilities' conditions in developing countries limit the use of artificial sun instrument. It is very well known that the description of current-voltage (I-V) and power-voltage (P-V) in different environmental conditions can characterize a solar cell. However, some common commercial PV panels in rural area don't present this information and the knowledge of these curves is not enough to estimate the actual generated power of the panels in operating condition. Therefore, an experimental testing system is necessary to have the capability and the reproducibility in environmental conditions for comparing several algorithms and characterizing panel.

At this day, it's not possible to get locally solar irradiation information's in Douala town, so designing an acquisition station for potential energy estimation needs was paramount. The climatic magnitudes are acquired by three sensors that convert them into electrical signals to be interpreted by the computing and processing which is a Mega Arduino module. Two other sensors of electrical quantities are installed at the output of the photovoltaic module. The five sensors implemented are:

- Current sensor (ACS712-5A)

- Voltage divider bridge (1/5 resistors of $10 \mathrm{~K} \Omega$ )

- Temperature and humidity (DHT22)

- Wind speed (Adafruit Anemometer 1733)

- Irradiation (Apogee pyrometer SP-110)

The output power is also calculated after measuring the voltage and current of the panel. These values are displayed on a $20 \times 4 \mathrm{LCD}$ for viewing. The same measured values are stored in a $4 \mathrm{~GB}$ memory card as a text file, which will be imported into the MATLAB software for processing. An overview during the tests carried out at the University Institute of Technology (UIT) of Douala (coordinates are: $4^{\circ} 05^{\prime} 57,987^{\prime \prime} \mathrm{N} ; 9^{\circ} 74^{\prime} 33,117^{\prime \prime} \mathrm{E}$ ) before and after fixing on a roof is presented in Figure 1.

Consequently, the acquired acquisition station makes it possible to obtain variations in electrical and meteorological quantities such as those observed in Figure 2. 

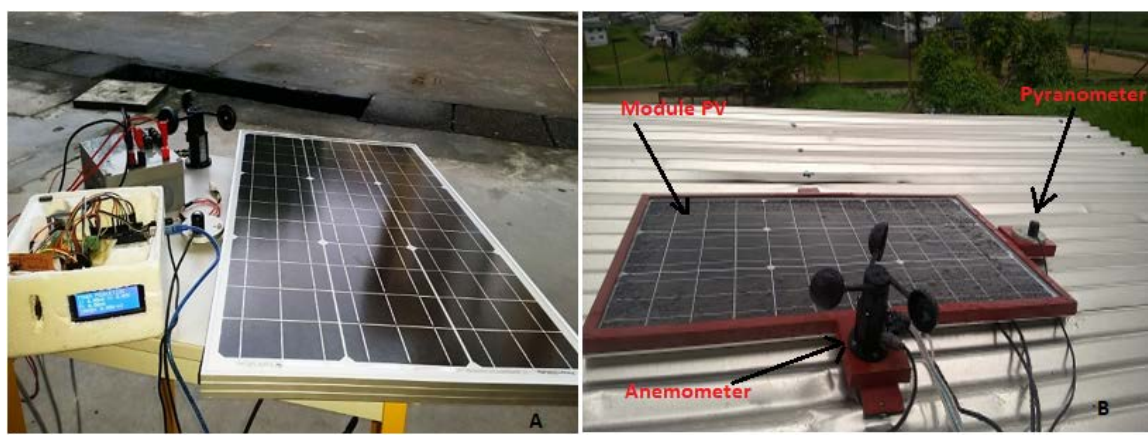

Figure 1. Acquisition station during the test (A) and after deployment (B) PV module, irradiation sensor, wind speed-UIT of Douala.

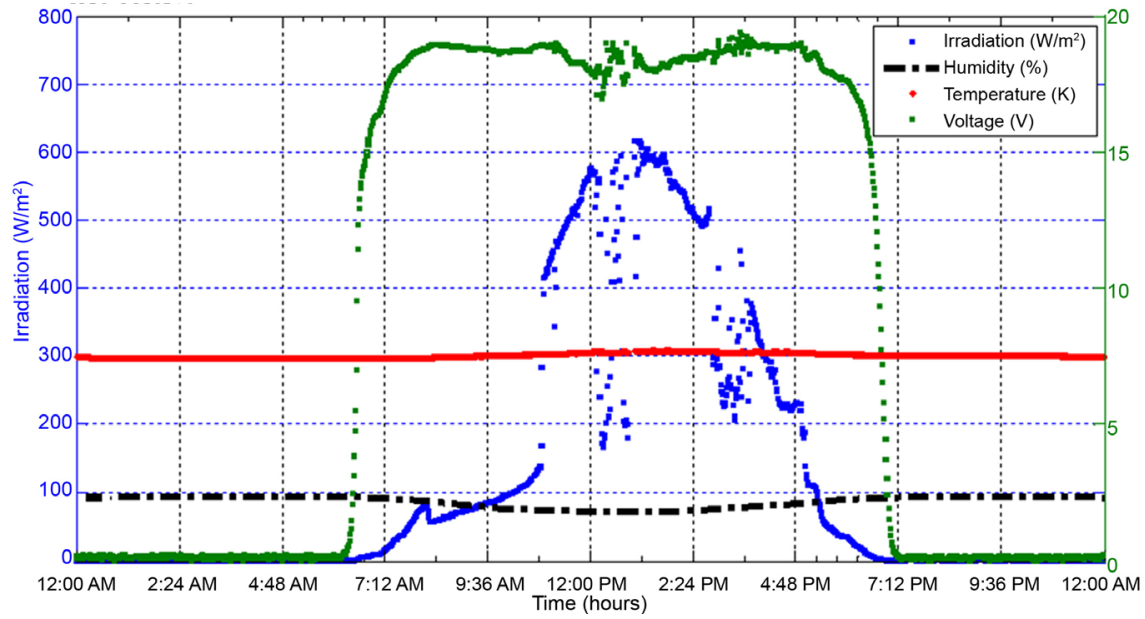

Figure 2. Physical quantities measured for a typical day (August-most unfavorable month).

The validation of the acquisition is verified. The temporal data acquired with a fixed resistive load allow obtaining the power according to the output voltage ( $P$ $=k \times U^{2}$ ). Polynomial recognition results in $k=0.2107$ (at $95 \%$ confidence bounds) either: $R_{\text {measured }}=4.746 \Omega$. The relative error of our measurement can then be appreciated: $\pm 0.97 \%$.

Figure 2 presents a range of humidity between $85 \%-99 \%$. For one year of acquisition, the humidity value across a day is usually so high in the region, even if the temperature is at his highest value. Thus, the acquisition reveals that the humidity undoubtedly very high varies slightly but inversely with the temperature.

Hypotheses such as the increase of the power with the irradiation, and the increase of temperature of the cells creating an undesirable effect on the electrical efficiency [16] of the panel are verified after the acquisition.

\subsection{Relationship between PV Power Output and Environmental Values}

Meteorological parameters variation depends on the geographical location. But, no similar impact of a meteorological parameter exists on the PV power generation at different geographical locations [17]. Consequently, the relation between 
meteorological parameters and PV power output will not be the same in different locations. However, the performance of a model is very dependent on the correlation between the input and output values of the model.

Not only solar irradiation is an input parameter, but also other weather parameters, including atmospheric temperature, module temperature, wind speed and direction, and humidity, are considered as potential parameters for estimating the PV power output [17].

In this case, the study of the correlation of the dissimilar meteorological inputs, such as solar irradiance, atmospheric temperature, module temperature, wind speed and direction, and humidity, with PV power output, is important. The correlation might be positive or negative. The strongly correlated input variables should be used as an input vector to improve the model, and the weakly correlated input vector data should be declined.

The global solar horizontal irradiance and PV power output of a typical day can be correlated. In a clear-sky day means a normal day, the PV power output is strongly harmonized with the solar irradiance curve. Therefore, a similar pattern is observed for PV power output and solar irradiance in any weather condition. Figure 3 shows the high positive correlation between solar irradiance and PV power output in weak solar condition. Like hypothesis, the PV power output is not highly strongly correlated with the solar irradiance on an abnormal day, like a cloudy or rainy day [17]. However, it is strongly matched in Figure 4. So, solar irradiance is an important input vector [18] in evolving an appropriate PV power model due to its high correlation.

Concerning the temperature factor, in the period of the absence of daylight, the PV power output is absent, and no impact of atmospheric temperature exists on the PV power [17]. Thus, atmospheric temperature form variation throughout the day follows the PV power only during the daylight period.

Figure 5 shows the relationship between the atmospheric temperature and the

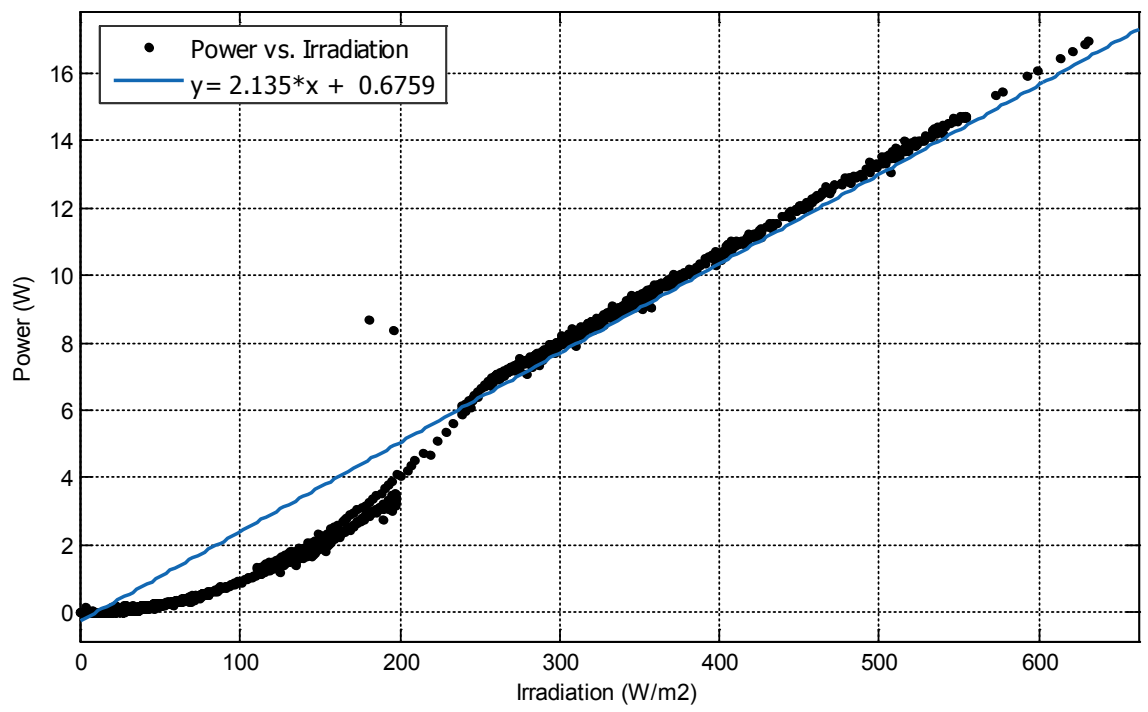

Figure 3. Power output variation with solar irradiation $\left(\mathrm{R}^{2}=0.9616\right)$ from data acquisition. 


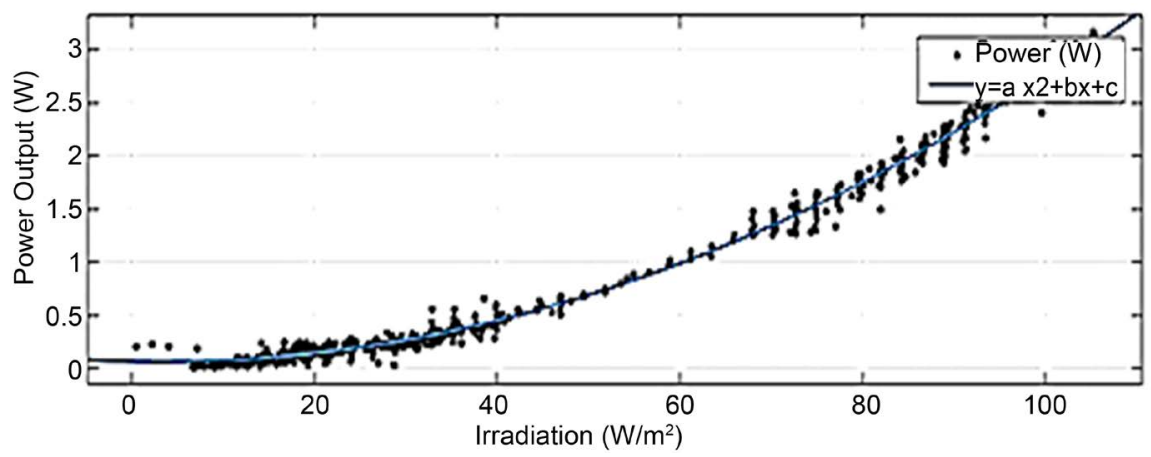

Figure 4. Power output variation with solar irradiation in cloudy conditions (Polynomial of $2^{\text {nd }}$ degree $R^{2}=0.9941$ ).

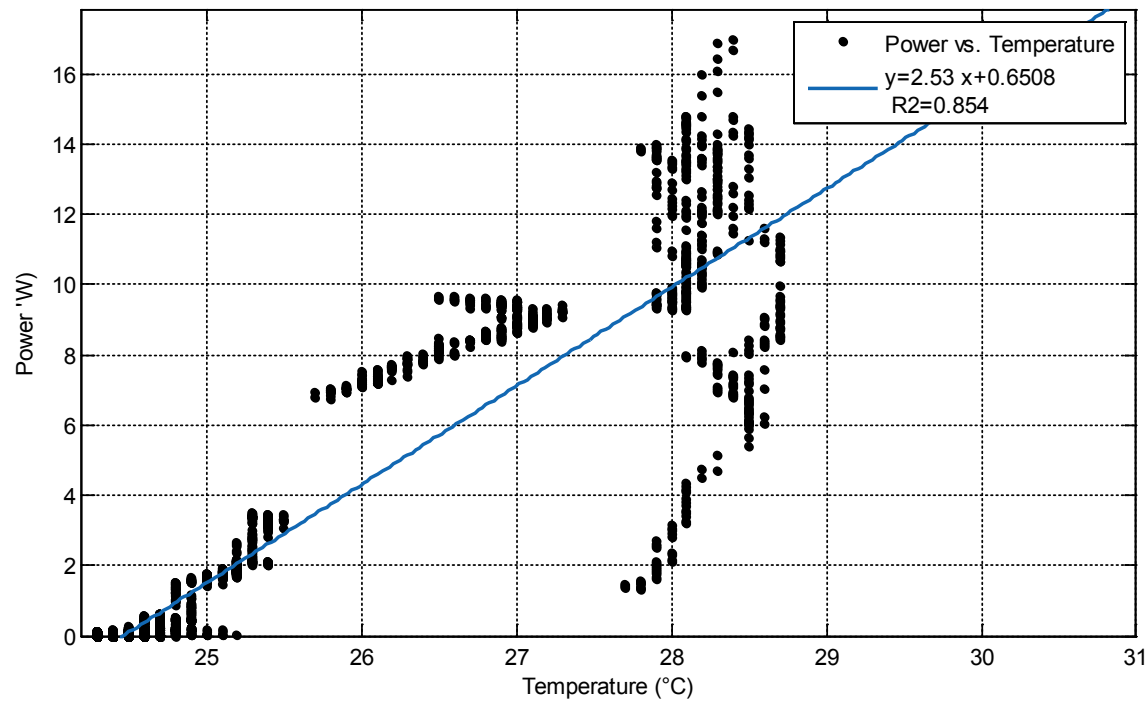

Figure 5. Power output variation with temperature from data acquisition.

PV power output. The correlation is not high, like for the irradiance input, but not so low.

Therefore, the atmospheric temperature can be used as a significant input to find the projecting model of the PV power output.

The other meteorological quantities measured and recorded by the system (wind speed, humidity) also affect the performance of the solar panel. For reasons of calculation speed and exploration space, these quantities will not be taken as input vectors in the models of this paper. But will serve to interpret this ending work and can be used to reanalyze models if they are introduced in other upcoming works.

\section{Modeling of LW-MS50 and Simulations}

As this work is carried out for a technical-economical optimization for the rural areas of the tropical country, the PV chosen module, for its availability and his low cost on the market, is the LW-MS50. Table 1 presents the characteristics of the nameplate. 
Table 1. Characteristics of panel LW-MS50.

\begin{tabular}{ccc}
\hline Designation & Abbreviation & Values \\
\hline Maximum power & $P_{\max }$ & $50 \mathrm{~W}$ \\
Voltage at Pmax & $V_{m p}$ & $17.95 \mathrm{~V}$ \\
Current at Pmax & $I_{m p}$ & $2.78 \mathrm{~A}$ \\
Short Circuit current & $I_{s c}$ & $3.1 \mathrm{~A}$ \\
Open circuit voltage & $V_{o c}$ & $21.2 \mathrm{~V}$ \\
Temperature coefficient at Voc & $K_{V}$ & $(-0.34) \% /{ }^{\circ} \mathrm{C}$ \\
Temperature coefficient at Isc & $K_{i}$ & $(0.037) \% /{ }^{\circ} \mathrm{C}$ \\
Temperature coefficient of power & $K_{p}$ & $(-0.48) \% /{ }^{\circ} \mathrm{C}$ \\
Normal Operating Cell Temperature & $\mathrm{NOCT}$ & $47^{\circ} \mathrm{C} \pm 2{ }^{\circ} \mathrm{C}$ \\
\hline
\end{tabular}

\subsection{Modeling the Photovoltaic Module}

Predicting the behavior of $\mathrm{I}-\mathrm{V}$ and P-V curves for photovoltaic (PV) generation is possible through mathematical models for photovoltaic cells. Several physicians have proposed more evolutionary models that present better accuracy for different purposes [9] [19] [20] articles proposed one extra diode to represent the effect of the recombination of carriers. [14] used a model with a current generator and two diodes in parallel. [21] proposed a three-diode model to include the influence of effects which are not considered by the previous models.

However, a model with a single diode offers a good compromise between simplicity and accuracy [22] and this model is widely used [23]. Sometimes basically or with other components, but always with the basic structure of a current source and a diode in parallel. The usefulness of the single-diode model with a method for adjusting the parameters, and considering experimental data is proposed in this paper to really perform this model.

Three equivalent circuit models can be used to describe a single-diode model [24].

The first is the ideal solar cell, also called 1M3P model (Single Mechanism, Three Parameters). It is an ideal model (Figure 6), where the solar cell can be simply modeled by a p-n junction in parallel with a current source that is associated to the photocarriers generated.

By adding a series resistance, the model will be close to the real module behavior. This proposition is known as the 1M4P model (Single Mechanism, Four Parameters), takes into account the influence of contacts by means of a series resistance $R_{s}$. The $R_{s}$ resistance is the sum of several structural resistances of the device. In fact, it is proportional to the number of solar cells in the panel [25]. The unknown parameters of this model are: $I_{P V}, I_{S}$ a and $R_{S}$.

These models are not accurate enough. A shunt resistance exists, and it is necessary to introduce one more realistic solar cell model, with series and shunt resistances, like 1M5P model (Single Mechanism, Five Parameters), shown in Figure 6. The parallel shunt resistor $\left(R_{p}\right)$, represents the influence of the leakage 


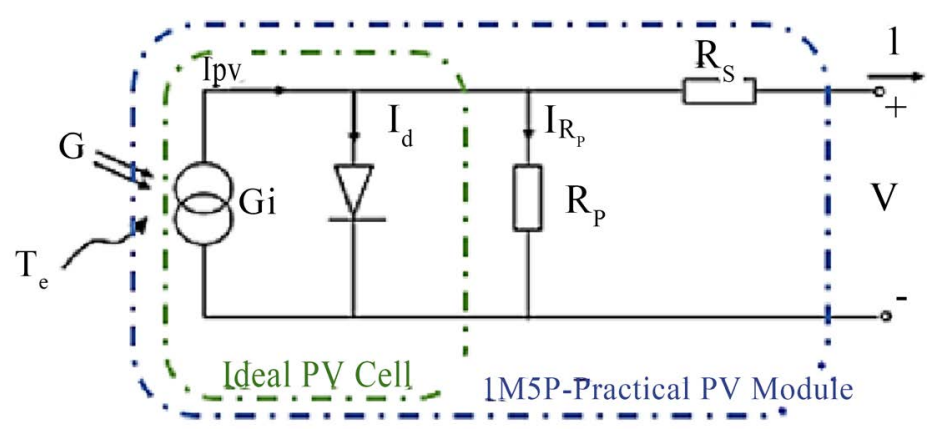

Figure 6. Electrical model of solar module.

current of the $p$ - $n$ junction and depends on the fabrication method of the photovoltaic cell. This model has five parameters: $I_{P V}, I_{o}, a, R_{S}, R_{S h}$, are linked by Equation (1).

$$
I=I_{p v}-I_{o}\left[\mathrm{e}^{\left(\frac{V+R_{s} I}{a * N_{s} * V_{t}}\right)}-1\right]-\frac{V+R_{s} * I}{R_{p}}
$$

with: $I_{p v}$ and $I_{s}$ like photovoltaic and saturation currents of the module; $V_{t}=$ $k T / q$ : the thermal voltage of the module; $N_{s}$ cells connected in series; a: diode ideality constant.

The practical photovoltaic device presents a hybrid behaviour, which may be of current or voltage source depending on the operating point, as shown in Figure 7. There is a series resistance $R_{s}$ whose impact more when the PV module functions in the voltage source region, and a parallel resistance $R_{p}$ with stronger influence in the current source region of operation.

The value of $R_{p}$ is generally high and some authors [26] [27] neglect this resistance to simplify the model. The value of $R_{s}$ is very low and sometimes this parameter is also neglected [28]. So, we will develop in first a model with manufacturer parameters and without $R_{p}(1 \mathrm{M} 4 \mathrm{P})$.

\subsubsection{Model 1M4P}

As above announced, four parameters should be found:

- It is difficult to determine light-generated current $\left(I_{p v}\right)$ of the elementary cells, without the series and parallel resistances. Datasheets only notify on the nominal short-circuit current $\left(I_{s c, n}\right)$, which is the maximum current available at the PV module output. The hypothesis $I_{s c} \approx I_{p v}$ is frequently used in photovoltaic models. In fact, the series resistance is less than $1 \Omega$, and the parallel resistance is more than $100 \Omega$ in practical devices. Without temperature influence [29] provides Equation (2) where $I_{p v}$ depends on real irradiance $(G)$ :

$$
I_{p v}=I_{s c} \times \frac{G}{G_{o}}
$$

- It's considering that our solar cell is like a luminescent diode, to obtain $I_{o}$. Therefore, during obscurity $\left(I_{\text {Diode }}=0 \mathrm{~A}\right.$ ) the output voltage is the $V_{o c}$ and the output current is the short-circuit current $I_{s c}[15]$. 


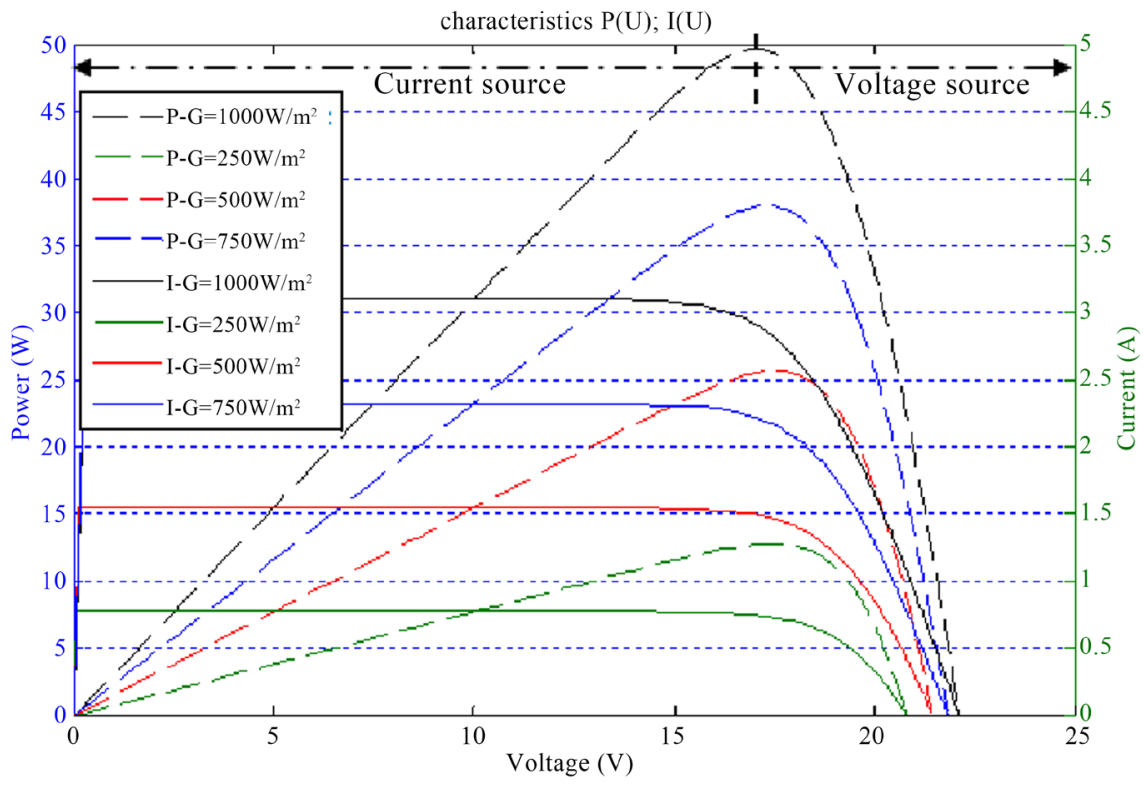

Figure 7. Power and current-voltage characteristics-1M4P.

$$
V_{o c}=V_{t} \times \ln \left(\frac{I_{c c}}{I_{s}}+1\right)
$$

In this way, we obtain:

$$
I_{o}=\frac{I_{c c}}{\exp \left(\frac{V_{c o}}{N_{s} * V_{t}}\right)-1}
$$

The Equation (4) in Equation (1) at the maximum power point gives us:

$$
R_{s}=a N_{s} V_{t} \times \ln \left[\frac{\left(\frac{I_{s c}-I_{m p}}{I_{o}}+1\right)}{I_{m p}}\right]-\frac{V_{m p}}{I_{m p}}
$$

These previous equations lead to get characteristic curves of $\mathrm{I}-\mathrm{V}$ and $\mathrm{P}-\mathrm{V}$ like shown in Figure 7.

To show the effect of irradiance on the performance of a module, the temperature is kept fixed at $25{ }^{\circ} \mathrm{C}$ and the values of irradiance are changed to different values. The variation of the $I(V)$ characteristics with irradiance is shown in Figure 7. Irradiance has the principal effect on the short circuit current and indeed the relationship between irradiance and the short circuit current is a linear one in this model. The simulations lead to the validation of the model according to Figure 7, when the irradiation decreases, the maximum power decreases also.

\subsubsection{Cell Currents with Classic Temperature Adjustments}

The light generation current of the photovoltaic cell depends linearly on the solar irradiation and is also influenced by the temperature according to the following Equation (6) [30]: 


$$
I_{p v}=\left(I_{p v, n}+K_{i} \Delta_{T}\right) \frac{G}{G_{n}}
$$

where: $I_{p v, n}[\mathrm{~A}]$ is the light-generated current at the nominal condition (usually $25{ }^{\circ} \mathrm{C}$ and $1000 \mathrm{~W} / \mathrm{m}^{2}$ ), $\Delta_{T}=T-T_{n}$ (being $T$ and $T_{n}$ the actual and nominal temperatures of cell $[\mathrm{K}]), G\left[\mathrm{~W} / \mathrm{m}^{2}\right]$ is the irradiation on the device surface, and $G_{n}$ is the nominal irradiation.

The saturation current $I_{0}$ of the photovoltaic cells that compose the device depends on the saturation current density of the semiconductor $\left(J_{o}\right.$, generally given in $\left.\left[\mathrm{A} / \mathrm{cm}^{2}\right]\right)$ and on the effective area of the cells [31].

$$
I_{0}=I_{0, n}\left(\frac{T_{n}}{T}\right)^{3} \exp \left[\frac{q E_{g}}{a k}\left(\frac{1}{T_{n}}-\frac{1}{T}\right)\right]
$$

where $E_{g}$ is the bandgap energy of the semiconductor $\left(E_{g} \approx 1.12 \mathrm{eV}\right.$ for the polycrystalline-Si at $25^{\circ} \mathrm{C}$ ), and $I_{0, n}$ is the nominal saturation current as:

$$
I_{0, n}=\frac{I_{S C, n}}{\exp \left(\frac{V_{O C, n}}{a N_{s} V_{t}}\right)-1}
$$

The values of $E_{g}$, and $J_{o}$ are infrequently available for commercial photovoltaic arrays. In the following, the nominal saturation current $I_{0, n}$ is indirectly obtained from the experimental data through Equation (8), which is obtained by evaluating Equation (1) at the nominal open-circuit condition, with $V=V_{o c, n}, I=0$, and $I_{p V} \approx I_{s c, n}$.

The photovoltaic model described in the previous section can be improved with temperature coefficients.

The saturation current $I_{0}$ is strongly dependent on the temperature and we propose a different approach to express the dependence of $I_{0}$ on the temperature. We obtained the Equation (9) from (8) by including in the equation the current and voltage coefficients $K_{i}$ and $K_{r}$.

$$
I_{0}=\frac{I_{S C, n}+K_{i} \Delta_{T}}{\exp \left(\frac{V_{O C, n}+K_{V} \Delta_{T}}{a V_{t}}\right)-1}
$$

This equation withdraws the model error at the vicinities of the open-circuit voltage point and consequently at other regions of the I-V curves and will simplify the model.

The realism of this equation has been tested with all three single-diode models by simulation.

Normally, the voltage/temperature coefficient $K_{V}$ brings important information necessary to achieve the best possible I-V curve fitting for temperatures different from the nominal value. Nonetheless, the coefficients $K_{V}$ and $K_{i}$ from the manufacturer's datasheet appear in Equation (9). And we will search if this correction introduced with Equation (1), allows getting closer to the real character in our climatic conditions in the tropical environment. 
The value of the diode constant $n$ will be arbitrarily chosen. Many authors discuss ways to estimate the correct value of this constant [22]-[32]. Usually, $1 \leq$ $a \leq 1.5$ and the choice depends on other parameters of the I-V model. Some values for $n$ are found in [30] based on empirical analysis. As [22] says, there are different opinions about the best way to choose $a$. In fact, the value $\mathrm{n}$ is totally empirical, and an initial value of $a$ can be chosen in order to improve the model. The value of $n$ can be later modified to improve the model fitting if necessary.

\subsubsection{Model 1M5P: $R_{S}, R_{p}$ and $a$ Values Solved by Iterative Methods}

Equation (1) does not have a direct solution because: $I=g(V, I)$ and $V=f(I, V)$. This transcendental equation can be solved by a numerical method. The I-V points are easily obtained by numerically solving

$$
g(V, I)=I-f(V, I)=0
$$

for a set of $V$ values and obtaining the corresponding set of $I$ points. And the couple $\left(R_{s}, R_{p}\right)$ is still unknowing.

$R_{s}$ and $R_{p}$ may not be solved separately if we are looking for a realist I-V model. $R_{p}$ can be found if we have a value of $R_{s}$.

To reach these values, methods in the literature, and the proposed method are run out.

\section{1) Villalva's Method}

This described method [33] allows only finding $R_{s}$ and thus $R_{p}$ using the point of maximum power. Not only with the I-V curve but also with the P-V (power vs. voltage) curve, which must match the experimental data too.

The target is to find the value of $R_{s}$ (and later $R_{p}$ ) that the highest value of the $\mathrm{P}-\mathrm{V}$ curve coincides with the experimental peak power at the $\left(V_{m p}, I_{m p}\right)$ point. This requires several iterations until $P_{\max , m}=P_{\max , e}$.

Just the peak power value is required, and the iterative process incremented Rs starting from zero and adjusting the P-V curve to match the experimental data. Plotting the P-V and I-V curves require solving Equation (1) on the interval

$$
\left\{\begin{array}{l}
0 \leq I \leq I_{s c, n} \\
0 \leq V \leq V_{o c, n}
\end{array} .\right.
$$

Subsequently, different values of a can be explored to improve the model fitting. In fact, this constant affects the I-V characteristic and his variation modifies the precision of this curve [33].

The Equation (6) and Equation (9) are used to obtain $I_{p V}$ and $I_{o}$, and by considering that $I_{p v, n}$ is giving by Equation (10):

$$
I_{p v, n}=\frac{I_{s c, n}\left(R_{s}+R_{p}\right)}{R_{p}}
$$

Equation (10) is written at the maximum power point of Equation (1)

$$
R_{p}=\frac{V_{m p}\left(V_{m p}+R_{S} I_{m p}\right)}{V_{m p} I_{P V}-V_{m p} I_{0}\left[\exp \left(\frac{q}{K T} \frac{\left(V_{m p}+I_{m p} R_{S}\right)}{a N_{S}}\right)\right]+V_{m p} I_{0}-P_{\max , e}}
$$


The adjusting of $R_{s}$ and $R_{p}$ is based on the fact that there is an only couple ( $R_{s}$, $R_{p}$ ) that warranties the maximum power calculated by the I-V model of Equation (1). $P_{\max , m}$ is equal to the maximum experimental power from the datasheet, and $P_{\max , e}$ is the measured maximum power point (MPP). Equation (12) shows this purpose: $P_{\max , m}=P_{\max , e}=V_{m p} I_{m p}$ at the $\left(V_{m p}, I_{m p}\right)$ point of the I-V curve.

$$
P_{\max , m}=V_{m p}\left\{I_{P V}-I_{0}\left[\exp \left(\frac{q}{K T} \frac{\left(V_{m p}+R_{S} I_{m p}\right)}{a N_{S}}\right)-1\right]-\frac{V_{m p}+I_{m p} R_{S}}{R_{p}}\right\}=P_{\max , e}
$$

Figure 8 illustrates how this iterative process works when $R_{s}$ increases, the $\mathrm{P}-\mathrm{V}$ curve moves to the left and the peak power $\left(P_{\max , m}\right)$ goes towards the experimental MPP.

Also the same concept for graphically finding the solution for $R_{s}$ is performed.

For each fixed $R_{s}$, the curve $P(V)$ is plotted by varying $V$ from 0 to $V_{o c}$ Accordingly, for each series of $P\left(V, R_{s}\right)$, a higher value result. We can then draw the curve of the maximum values of $P(V)$ corresponding to each $R_{s}$. The minimum of this curve corresponds to $P_{\max , e}$ and to the value of $R_{s}$ sought. Figure 9 shows a plot of $P_{\max , m}$ as a function of $R_{s}$.

At this stage of work, $P(V)$ and $I(V)$ curve are also adjusted to three remarkable points for $V=0, V_{m p}$, and $V_{o c}$

\section{2) Modified Newton-Raphson Method}

This iterative method is common to find the root of a function $f\left(R_{s}\right)$. A value of $R_{s}$ is chosen and incremented until the stop condition isn't obtained. If the value of $f\left(R_{s}\right)$ divided by its derived function is less than the tolerance value, then the value of $R_{s}$ is retained and $R_{p}$, with the other values are computed. Another test cycle can be used to explore different values of the coefficient $a$. Interval $1 \leq$ $a \leq 1.5$, is usually used [33].

Figure 10 presents the applied algorithm. The algorithm proposed by [34] is used in with the following modification. The value of $a$ is explored to minimise the error between $P_{\max }$ from $\left(R_{s}, R_{p}\right)$ solved and $P_{\max }$ from the datasheet.

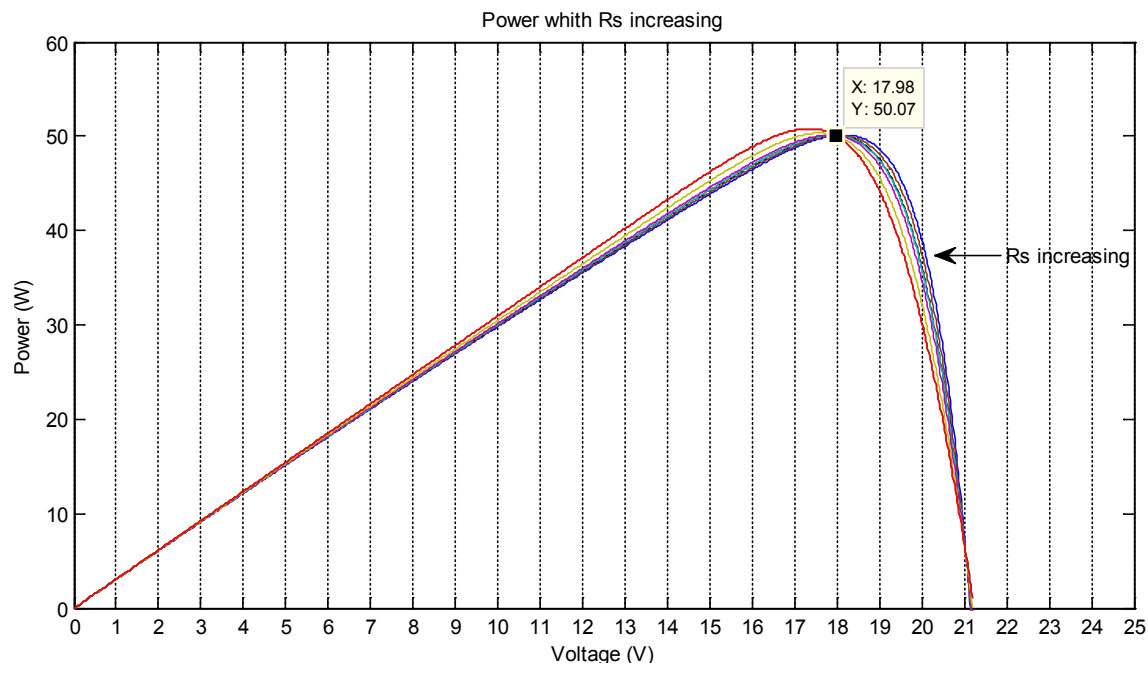

Figure 8. $P(V)$ curves with different values of $R_{s}$. 


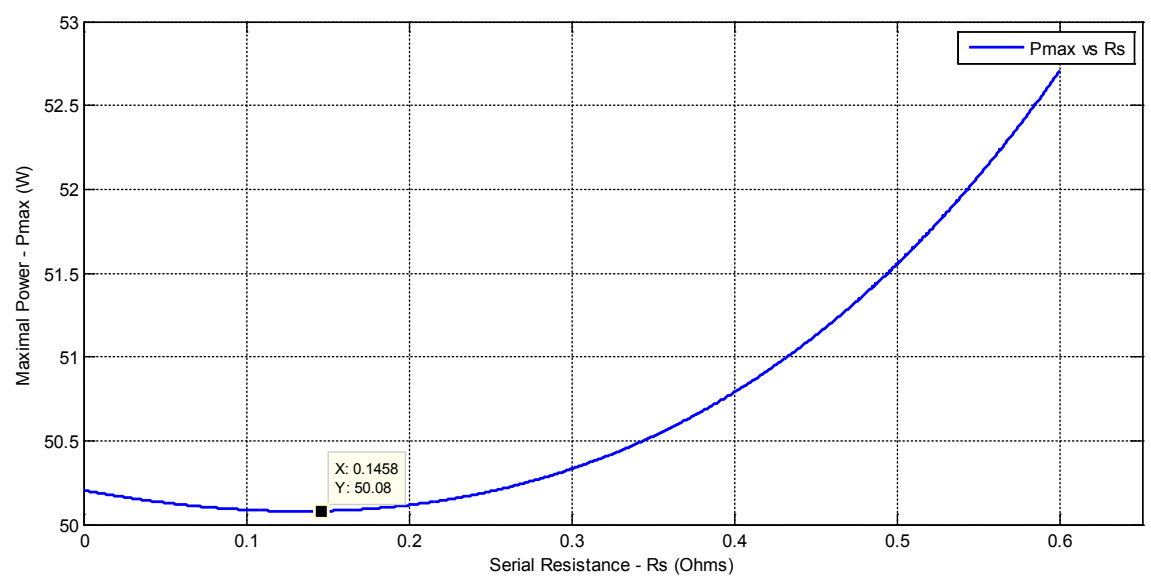

Figure 9. Curve of the maximum powers for different $R_{s}$.

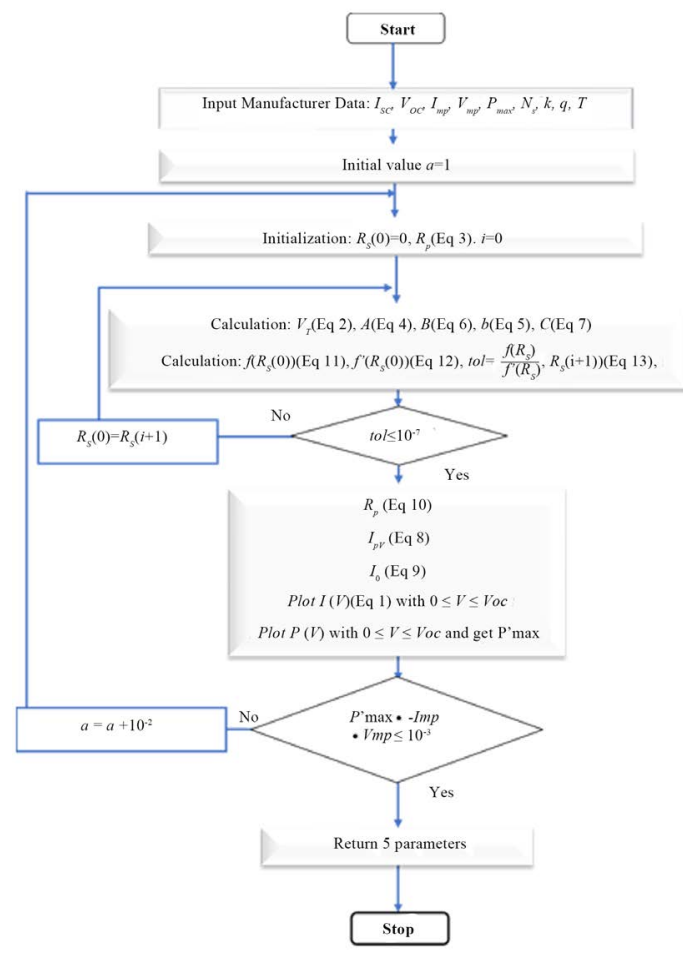

\begin{tabular}{|c|c|}
\hline Equations & Formulations \\
\hline 1 & $I=I_{p v}-I_{0}\left\{\exp \left[\frac{q \cdot\left(V+I \cdot R_{S}\right)}{a \cdot N_{S} \cdot k \cdot T}\right]-1\right\}-\frac{V+I \cdot R_{S}}{R_{p}}$ \\
\hline 2 & $V_{T}=\frac{a \cdot N_{S} \cdot k \cdot T}{q}$ \\
\hline 3 & $R_{P}=\frac{V_{m p}}{I_{s c}-I_{m p}}-\frac{V_{o c}-V_{m p}}{I_{m p}}$ \\
\hline 4 & $\mathcal{A}=\exp \left[\frac{V_{O C}}{V_{T}}\right]-1$ \\
\hline 5 & $b=1+\frac{R_{S}}{R_{p}}$ \\
\hline 6 & $\mathcal{B}=\exp \left[\frac{I_{S c} R_{S}}{V_{T}}\right]-1$ \\
\hline 7 & $\mathcal{C}=\exp \left[\frac{V_{m p}+I_{m p} R_{S}}{V_{T}}\right]-1$ \\
\hline 8 & $I_{p v}=\frac{b \cdot \mathcal{A} \cdot I_{s c}-\mathcal{B} \cdot \frac{V_{0 C}}{R_{P}}}{\mathcal{A}-\mathcal{B}}$ \\
\hline 9 & $I_{0}=\frac{I_{p v}}{\mathcal{A}}-\frac{V_{O C}}{\mathcal{A} \cdot R_{p}}$ \\
\hline 10 & $R_{P}=\frac{V_{o c}(\mathcal{C}-\mathcal{B})-V_{m p}(\mathcal{A}-\mathcal{B})}{I_{m p}(\mathcal{A}-\mathcal{B})-I_{s c}(\mathcal{A}-C)}-R_{S}$ \\
\hline 11 & $\begin{aligned} f\left(R_{s}\right)=V_{m p}(\mathcal{C} & +1)\left[I_{s c} \cdot V_{o c}-I_{s c} \cdot V_{m p}-I_{m p} \cdot V_{o c}\right]-I_{s c} \cdot V_{m p} \cdot V_{T}(\mathcal{A}-\mathcal{C})-I_{m p} \cdot V_{o c} \cdot V_{T}(\mathcal{B}-\mathcal{C}) \\
& +2 \cdot I_{m p} \cdot V_{m p} \cdot V_{T}(\mathcal{A}-\mathcal{B})\end{aligned}$ \\
\hline 12 & $f^{\prime}\left(R_{s}\right)=\frac{V_{o c} \cdot V_{m p}(\mathcal{C}+1)}{V_{T}}\left[I_{s c}-I_{m p}\right]+I_{s c}(B+1)\left[V_{o c}-2 \cdot V_{m p}\right]+(\mathcal{C}+1)\left[I_{s c} \cdot V_{m p}-I_{m p} \cdot V_{o c}-\frac{I_{s c} \cdot V_{m p}^{2}}{V_{T}}\right]$ \\
\hline 13 & $R_{s}(i+1)=R_{s}(i)-\frac{f\left(R_{s}(i)\right)}{f^{\prime}\left(R_{s}(i)\right)}$ \\
\hline
\end{tabular}

Figure 10. Flowchart illustrating the proposed method and the computed equations

This proposed evaluation avoids using the calculation of the intensity error between the obtained current following a variation of the voltage and I-V curve given by the manufacturer's datasheet. Because, many manufacturers of common market solar panels don't provide I-V curves values, like for the chosen panel LW-MS50.

The decrease in calculation time by solving a single formulation instead of four or five equations instantaneously, and direct completion of the 5 targets parameters are the principal advantages.

3) Nonlinear Least Square Method (NLS)

This algorithm consists to modify multiple objective functions into a single 
objective function by using nonlinear least-square algorithm subjected:

$$
\min _{x}(h(x))=h_{1}(x)^{2}+h_{2}(x)^{2}+h_{3}(x)^{2}
$$

to constraint with lower and upper bound. Three equations through the three remarkable points of I-V curve $\left(0, V_{o c} V_{m p}\right)$ are used with two additional equations (Equation (12)):

$$
\left\{\begin{array}{l}
\left.\frac{\mathrm{d} P}{\mathrm{~d} V}\right|_{V_{m p}}=0 \\
\left.\frac{\mathrm{d} I}{\mathrm{~d} V}\right|_{I_{s c}}=-\frac{1}{R_{p}}
\end{array}\right.
$$

A set of three functions equal to zero is expressed, having each one for single variable $R_{p}, R_{s}$ and a (Equation (14)).

$$
\left\{\begin{array}{l}
h_{1}(x)=0=-I_{m p}+I_{s c}-\frac{V_{m p}+I_{m p} R_{s}-I_{s c} R_{s}}{R_{p}}-\left(I_{s c}-\frac{V_{o c}-I_{s c} R_{s}}{R_{p}}\right) \times \mathrm{e}^{\left(-V_{o c}+V_{m p}+I_{m p} R_{s}\right) / a N_{s} V_{t}} \\
h_{2}(x)=0=I_{m p}+V_{m p}\left(\frac{\frac{\left(V_{o c}-I_{s c} R_{p}-I_{s c} R_{s}\right) \times \mathrm{e}^{\left(-V_{o c}+V_{m p}+I_{m p} R_{s}\right) / a N_{s} V_{t}}}{a N_{s} V_{t} R_{p}}-\frac{1}{R_{p}}}{1+\frac{\left(-V_{o c}+I_{s c} R_{p}+I_{s c} R_{s}\right) \times \mathrm{e}^{\left(-V_{o c}+V_{m p}+I_{m p} R_{s}\right) / a N_{s} V_{t}}}{a N_{s} V_{t} R_{p}} R_{s}+\frac{R_{s}}{R_{p}}}\right) \\
h_{3}(x)=0=\frac{1}{R_{p}}+\frac{\frac{\left(V_{o c}-I_{s c} R_{p}-I_{s c} R_{s}\right) \times \mathrm{e}^{\left(-V_{o c}+I_{s c} R_{s}\right) / a N_{s} V_{t}}}{a N_{s} V_{t} R_{p}}-\frac{1}{R_{p}}}{1+\frac{\left(-V_{o c}+I_{s c} R_{p}+I_{s c} R_{s}\right) \times \mathrm{e}^{\left(-V_{o c}+I_{s c} R_{s}\right) / a N_{s} V_{t}}}{a N_{s} V_{t} R_{p}} R_{s}+\frac{R_{s}}{R_{p}}}
\end{array}\right.
$$

\section{4) Proposed Experimental Method}

The above methods are investigated to find the internal electrical characteristics of the panel. However, the I-V, and P-V curves plotted with these values do not always coincide with the real curves, measured at different temperatures and irradiation. Vivallva's method introduces an experimental power that may be different from that provided by the manufacturer. This experimental power should be measured in the STC $\left(G=1000 \mathrm{~W} / \mathrm{m}^{2} ; T=25^{\circ} \mathrm{C}\right.$, and solar spectrum at AM1.5). However, special testing equipment, like an expensive solar simulator and controlled environment, are necessary to satisfy to reach temperature and insulation of the STC [35].

Considering that, these climatic conditions cannot occur under the tropical climate and the low economic conditions of the study area. To overcome these drawbacks, this work proposes a method to find more accurate curves I-V and P-V based on the following steps:

- Calculation of the internal parameters of the solar cell, with the maximum power of the manufacturer to get $R_{p}, R_{s}$ at STC (via the Villalva's method or the other models above); 
- Extraction of temperature-related coefficients in the acquisition station database by fitting the $V_{o c}$ variation in temperature and irradiation, to Equation (15)

$$
V_{o c}(G, T)=V_{o c, n}+a N_{s} V_{t} \times \ln \left(\frac{G}{G_{n}} \alpha\right)+\beta_{V o c}\left(\frac{G}{G_{n}} \alpha\right)\left(T_{c e l l}-T_{n}\right)
$$

where the term $\frac{G}{G_{n}} \alpha$ represents the effective irradiance (in suns) of the panel (with $\alpha$ like the soiling factor), and $\beta_{V o c}$ the coefficient temperature at $V_{o c}$ - Plot I-V and I-V curves in the range: $0 \leq V \leq V_{o c}(G, T)$.

The different values of $V_{o c}$ for all the possible range of irradiation and temperature in the target area is obtained like a net by pattern recognition to fit the value of collected data for 1 year. Figure 11 presents the wavenet of $V_{o c}$ which can be easily used to retrieve $V_{o c}$ value for any couple of $(G, T)$ data.

The solved experimental coefficients of Equation (14) are: $a=0.9943 ; \alpha=$ $0.52727 ; \beta_{\text {Voc }}=-0.02235$.

This method allows also to get the a value, based on the measured and recorded values, and as such it fills the weakness of the Villalva's method, which does not calculate $a$, but proposes to check it later.

\section{Results and Discussion}

The 1M3P and 1M4P are so easy to compute. All the algorithms of 1M5P models are implemented in MATLAB Software. In different environmental conditions than STC, all the methods presented (except our experimental method) are plotted with the equations for temperature adjustment in Section 4.1.2. Figure 11 demonstrated the high fitting of the Villalva's and Modified Newton-Raphson methods from their I-V and P-V characteristics. NLS method presents I-V and P-V curves so near of the two others, but his $P_{\max }$ is just less than $P_{\max , e}$. The form and the maximal value of these curves stem of the value of the ideality factor $a$, who is near to 1 , but more than 1 (Table 2).

All the solution value of $R_{s}$ presented in Table 2 are in the interval [0.13, 0.18], like showed on Figure 9. NLS and modified Newton Raphson lead to solve

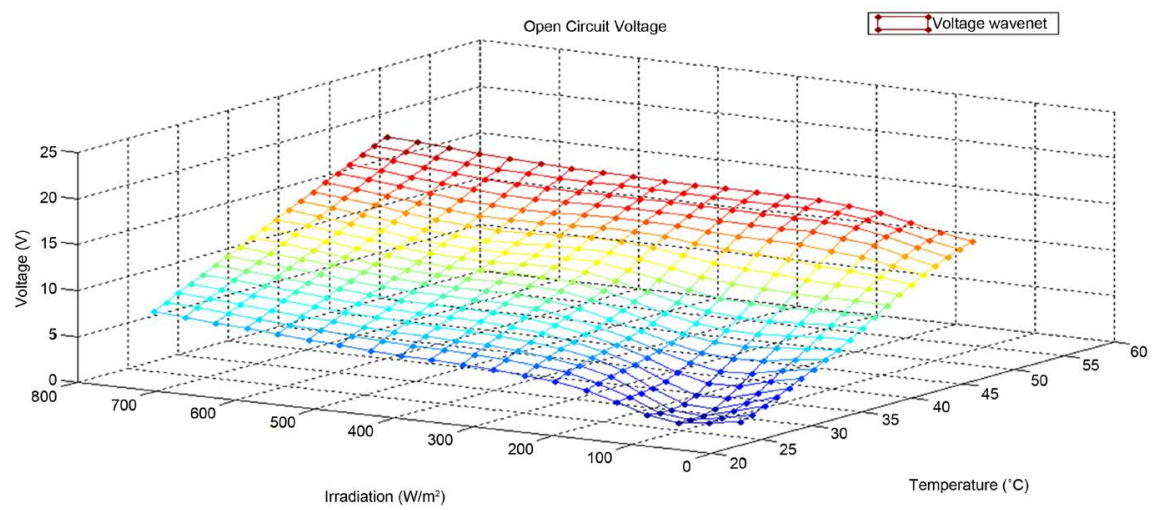

Figure 11. Voc wavenet vs irradiation and cell temperature. 
Table 2. Parameters estimation of PV module LW-MS50.

\begin{tabular}{cccc}
\hline & Villalva's Method & $\begin{array}{c}\text { Modified } \\
\text { Newton-Raphson method (with Leveng Marqued) method }\end{array}$ \\
\hline$R_{s}(\Omega)$ & 0.1458 & 0.1779 & 0.153 \\
$R_{p}(\Omega)$ & 110.4016 & 119.388 & 125.573 \\
$a$ & 1 (by default) & 1.023 & 1.196 \\
$I_{p v, n}(\mathrm{~A})$ & 3.1036 & 3.1046 & 3.10188 \\
$I_{o}(\mathrm{~A})$ & $3.515 \times 10^{-10}$ & $5.5 \times 10^{-10}$ & $1.419 \times 10^{-8}$ \\
Tolerance & $10^{-3}$ & $10^{-3}$ & $10^{-3}-10^{-6}$ \\
Calculation time(s) & 0.5 & 3.5 & 0.5 \\
\hline
\end{tabular}

3 or 5 parameters directly. The optimization of multi-objective function using NLS through the Leveng Marqued method for solving the parameter estimation of a PV panel has been well done and the results are useful, comparable to classic iterative methods and less time-consuming. Nevertheless, the accuracy of estimated values depends upon the chosen tolerance band and initial conditions. However, in reason, of his calculation time, his simplicity and his reproducibility, $R_{s}$ and $R_{p}$ from Villalva's method is used in our proposed experimental method and it's called 1M5P in the following comments and Figure 12.

As a global result, Figure 13 shows three kinds of single-diode model in I-V and $\mathrm{P}-\mathrm{V}$ curves, start from the model of 1M3P then this model adjusted with temperature $(1 \mathrm{M} 3 \mathrm{P}+\mathrm{T})$ and the model $(1 \mathrm{M} 5 \mathrm{P})$ adjusted in temperature with $\left(R_{s}, R_{p}\right)$ got by Villalva's method from experimental data of the manufacturer. The measured power points are also presented.

Simulation of $1 \mathrm{M} 4 \mathrm{P}, 1 \mathrm{M} 3 \mathrm{P}$ model and of $1 \mathrm{M} 3 \mathrm{P}+\mathrm{T}$ is done with temperature coefficients extracted from the datasheet. These curves show a variation with the $V_{o c}$ point following temperature variation. But the maximum simulated power is much higher than that measured. These models show their shortcomings in the face of reality.

On the other hand, the model 1M5P realized with the experimental data of the manufacturer but with the presence of $R_{s}$ and $R_{p}$ found through the iterative method, seems more realistic. The impact of $R_{p}$ (smaller than in the model $1 \mathrm{M} 4 \mathrm{P}$, because neglected $R_{p}$ comes to imagine a resistance in parallel very high like an open circuit) here considered creates a real fall of the maximum value of power and brings the $V_{o c}$ of this model near to the $V_{o c}$ measured under similar conditions of irradiation and temperature.

Regarding variations of $V_{o c}$ point through the models and their characteristics $\mathrm{I}-\mathrm{V}, \mathrm{P}-\mathrm{V}$, the value $V_{o c}(G, T)$ of our proposed experimental method very well matches the measured value when the output power is zero. The model is so accurate and overcomes the need claim by [36] to translate I-V and P-V for different values of $(G, T)$ than $(G, T)$ at STC.

Figure 13 and Figure 14 reveal that the so-called experimental model perfectly follows the electrical pattern of the module in different climatic conditions. The 

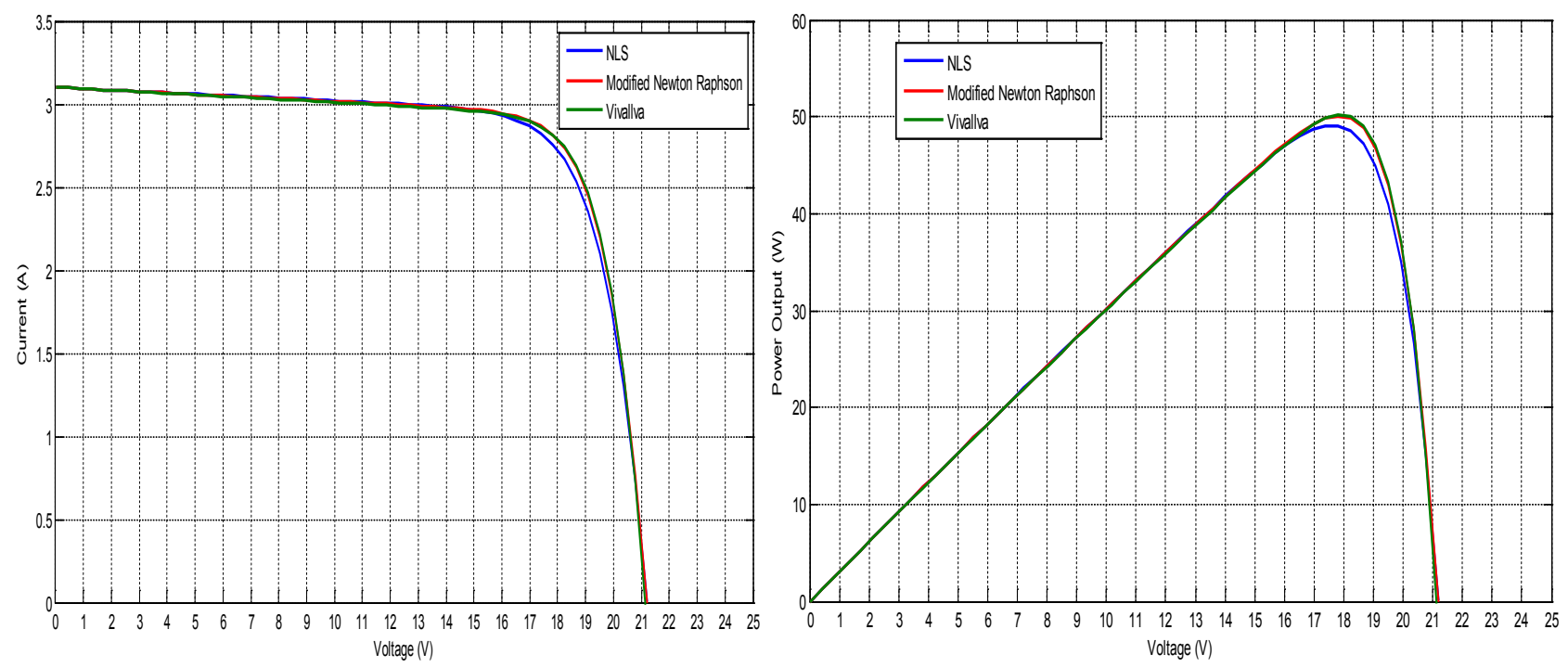

Figure 12. Comparison of three 1M5P models at STC.
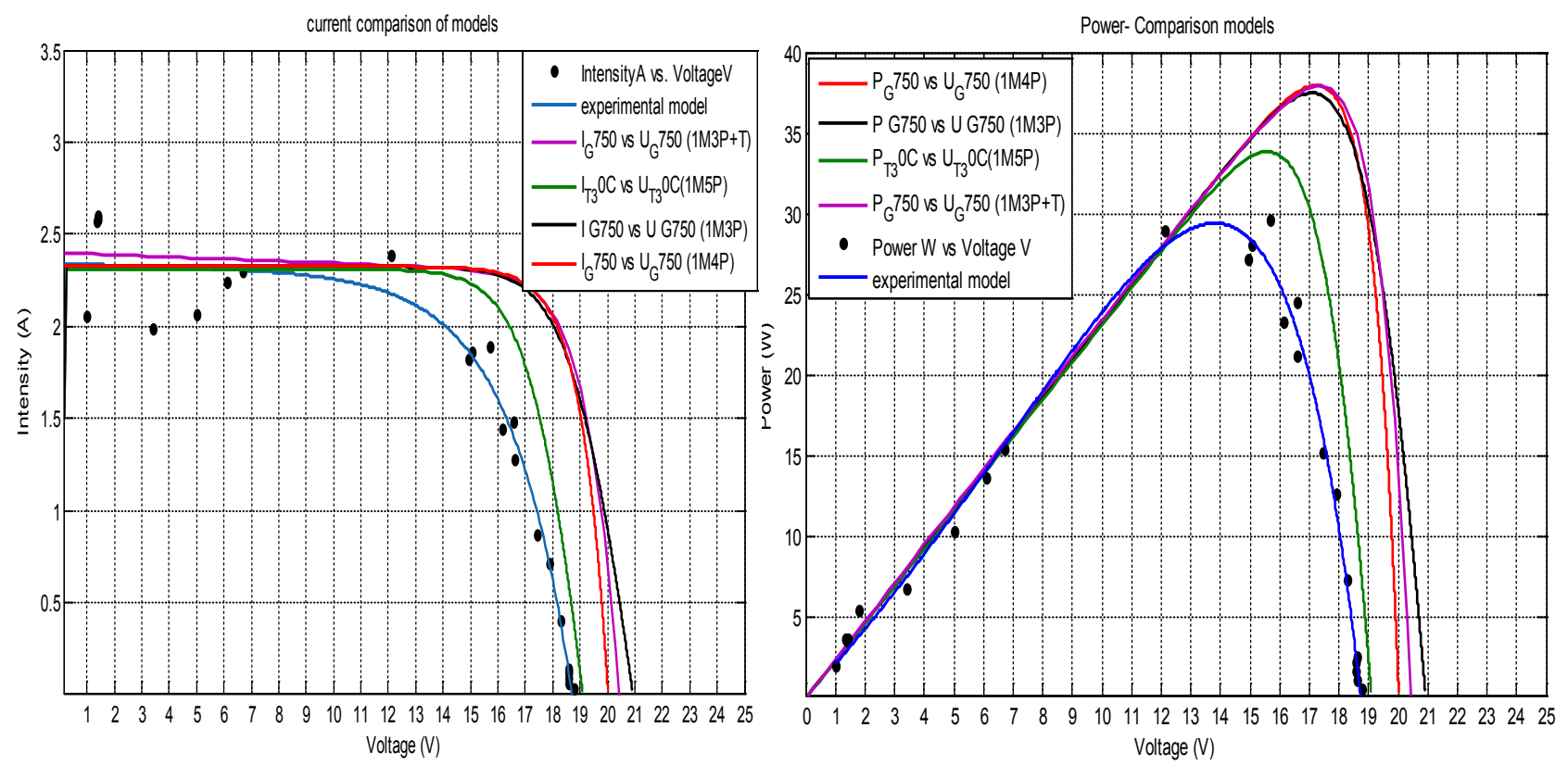

Figure 13. $P(V)$ and $I(V)$ characteristics of different built models and data measurement $G=750 \mathrm{~W} / \mathrm{m}^{2} ; T=30^{\circ} \mathrm{C}$.

calculated regression coefficient with a measured power output value is $R^{2}=$ 0.9869 . Some points seem remote, they could be due to the wind speed $(v)$ that was not stable $(v<1 \mathrm{~m} / \mathrm{s})$ and temperature changing, because the data are recorded every 1 minute. And the used temperatures for the simulation to obtain the characteristics $I(V)$ and $P(V)$ are the average during the variation period of the resistive load.

Figure 14 shows the mathematical P-V curve of $1 \mathrm{M} 5 \mathrm{P}$ (get with reference's points extracted from the datasheet), the proposed experimental method and measured curves in our tropical conditions of the LW-MS50 solar panel plotted at two different temperature and irradiation conditions. Figure 14 proves that 


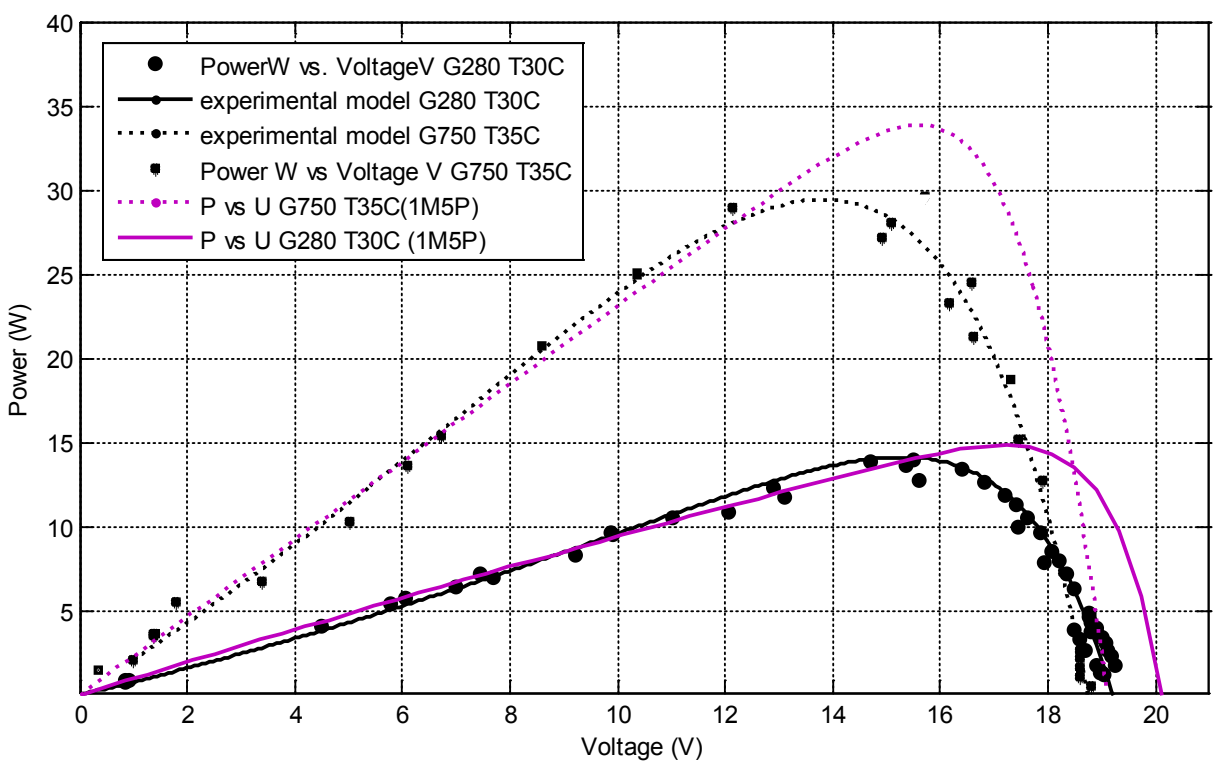

Figure 14. $P(V)$ curves comparison between proposed experimental model, 1M5P and measurement data.

1M5P (Vivallva's model) strongly variates in irradiation and temperature as expected: when irradiation increases, power increases, and for the temperature, the $V_{o c}$ point decreases.

However, use this model although coming from experimentation (of the manufacturer) would cause many errors for the sizing of mini-plants in tropical area. Like, a lack of electrical energy when it's not expected according to this model.

Comparison of power output from solar panel in real meteorological conditions and the model 1M5P with experimental datasheet points are done, with Equation (16).

$$
\text { |error } \mid=\frac{\left|P_{\text {measured }}-P_{\text {model }}\right|}{P_{\text {measured }}}[13]
$$

Table 3 represents the mean error and the standard deviation of these two groups of curves.

The relative error calculated is very high for large irradiation values. For both conditions, the error becomes increasing when the power decreases on the characteristic curve. It is the moment of operation in the area "source of voltage" of the photovoltaic generator.

Also, when the solar radiation is around $600 \mathrm{~W} / \mathrm{m}^{2}$ and temperature: $30^{\circ} \mathrm{C}$, the power is around $18 \mathrm{~W}$, and this is at $12 \mathrm{AM}$ to the worst month (August). But, the model with the manufacturer's data reflects a power greater than $25 \mathrm{~W}$ (To $25^{\circ} \mathrm{C}$ ), thus, a decrease of $38.7 \%$.

For this substitution, we can search for find other standards conditions for the geographical area, because the climatic data of the region over several years almost never coincide with the NOCT or the STC. 
Table 3. Relative errors (\%) between measured and 1M5P model power.

\begin{tabular}{ccccc}
\hline Panel powers & $\begin{array}{c}\text { Range of } \\
\text { relative error }\end{array}$ & Average & Standard deviation & Peak power errors \\
\hline$G=750 \mathrm{~W} / \mathrm{m}^{2} ; T=35^{\circ} \mathrm{C}$ & {$[-8.2719 ; 0.9704]$} & -1.8517 & 1.8940 & $-16.62 \%$ \\
$G=280 \mathrm{~W} / \mathrm{m}^{2} ; T=30^{\circ} \mathrm{C}$ & {$[-2.4673 ; 0.0463]$} & -0.1712 & 0.4022 & $-12.50 \%$ \\
\hline
\end{tabular}

\section{Conclusions}

Following the high relationship between the input variables: irradiation, and temperature and the output power of the solar panel, the MPO of PV modules can be planned, if the solar irradiation and the ambient temperature are known. In the point of view of internal modeling, several models of electrical behavior have been developed for a common solar panel presents in a rural area. Our proposed 1M5P experimental model with the experimental coefficients obtained for different $V_{o c}(G, T)$ values turned out to be the one with the least errors in front of the values from the acquisition station deployed for the cause. This model was developed by previously the resistances $\left(R_{s}, R_{p}\right)$, with iterative methods matching the manufacturer's experimental MPO. However, this iterative method simply computes at different environmental conditions with temperature coefficients of the manufacturer gives errors, which alternate between $10 \%$ $50 \%$ of the real power. Thus, the proposed experimental model leads to fit very well I-V and P-V curves from simulation to curves from measurement, and can be useful to obtain temperature coefficients on $V_{o c}$ and $I_{s c}$ more accurate in our environmental conditions than manufacturer's proposition. Also, the choice to use the equation from two features I-V, P-V and their derivate by time, like in the NLS method, for obtaining these internal parameters contrary to a single characteristic higher used in the literature, improved the coincidence with the characteristics measured under different meteorological conditions.

In deduction, although through the search for a linear correlation between temperature and power, the coefficient of Pearson is less than 1 but not negligible, this work validates the hypothesis that it is essential to consider temperature, in addition to irradiation, as an input vector to effectively estimate MPO. This raises the prospect of studying several solar cell temperature models as a function of irradiation, wind speed, ambient temperature and humidity, always in the same region. Also, our proposed method will be compared in future works with the Benchmark model to research the best experimental characterization and to simplify the optimization work of hybrid micro-central under tropical climate.

\section{Conflicts of Interest}

The authors declare no conflicts of interest regarding the publication of this paper.

\section{References}

[1] World Energy Outlook Team (2017) Energy Access Outlook 2017. International 
Energy Agency, Paris.

[2] ERA (2006) Rapport préliminaire pour le Cameroun. ENEFBIO.

[3] Green, A. and Emery, K. (2008) Short Communication Solar Cell Efficiency Tables (Version 31). Progress in Photovoltaics, 16, 435-440. https://doi.org/10.1002/pip.842

[4] Khan, M. and Iqbal, M. (2005) Dynamic Modeling and Simulation of a Small Wind-Fuel Cell Hybrid Energy System. Renewable Energy, 30, 421-439. https://doi.org/10.1016/j.renene.2004.05.013

[5] Markvart, T. and Castaner, L. (2003) Practical Handbook of Photovoltaics, 2nd Edition, Fundamentals and Applications, Elsevier, Amsterdam.

[6] King, D., Kratochvil, J., Boyson, W. and Bower, W. (1998) Field Experience with a New Performance Characterization Procedure for Photovoltaic Arrays. 2nd World Conference and Exhibition on Photovoltaic Solar Energy Conversion, Vienna, 6-10 July 1998.

[7] Kroposki, B., Marion, W., King, D., Boyson, W. and Kratochvil (2000) Comparison of Module Performance Characterization Methods. 28th IEEE PV Specialists Conference, Anchorage, 15-22 September 2000, 1407-1411. https://doi.org/10.2172/772437

[8] Woyte, A., Nijs, J. and Belmans, R. (2003) Partial Shadowing of Photovoltaic Arrays with Different System Configurations. Literature Review and Field Test Results. Solar Energy, 74, 217-233. https://doi.org/10.1016/S0038-092X(03)00155-5

[9] Gow, J.A. and Manning, C.D. (1999) Development of a Photovoltaic Array Model for Use in Power-Electronics Simulation Studies. IEE Proceedings-Electric Power Applications, 146, 193-200. https://doi.org/10.1049/ip-epa:19990116

[10] Xiao, W., Dunford, W. and Capel, A. (2004) A Novel Modeling Method for Photovoltaic Cells. Power Electronics Specialists Conference, Aachen, 20-25 June 2004, 1950-1956.

[11] Walker, G. (2001) Evaluating MPPT Converter Topologies Using a Matlab PV Model. Journal of Electrical and Electronics Engineering, 21, 49-56.

[12] Sera, D., Teodorescu, R. and Rodriguez, P. (2007) PV Panel Model Based on Datasheet Values. IEEE International Symposium, Vigo, 4-7 June 2007, 2392-2396. https://doi.org/10.1109/ISIE.2007.4374981

[13] Koumi, S., Njomo, D. and Moungnutou, I. (2012) Comparison of Predictive Models for Photovoltaic Module Performance under Tropical Climate. Telkomnika, 10, 245-256. https://doi.org/10.12928/telkomnika.v10i2.783

[14] Lin, L. (2004) Investigation on Characteristics and Application of Hybrid Solar/Wind Power Generation Systems. Hong Kong Polytechnic University, Hong Kong.

[15] Benmoussa, W.E.A. (2007) Etude comparative des modèles de la caractéristique courant-tension d'une cellule solaire au silicium monocristallin. Revue des Energies Renouvelables ICRESD-07, Tlemcen, 301-306.

[16] Ho'ang, A., Delinchant, B., et al. (2015) Renewable Energy Supply (PV) Integration with Building Energy Management: Modeling and Intelligent Control of Electrical Storage. Vietnam Academy of Science and Technology Journal of Science and Technology, 53, 173-187.

[17] Kumar, U.D., Soon Tey, K., Seyedmahmoudian, M., Mekhilef, S. and Yamani, I.I. (2018) Forecasting of Photovoltaic Power Generation and Model Optimization: A Review. Renewable and Sustainable Energy Reviews, 81, 912-928. 
https://doi.org/10.1016/j.rser.2017.08.017

[18] Huang, Y., Lu, J., Liu, C., Xu, X., Wang, W. and Zhou, X. (2010) Comparative Study of Power Forecasting Methods for PV Stations. Proceedings of International Conference on Power System Technology (POWERCON), Hangzhou, 24-28 October 2010, 1-6. https://doi.org/10.1109/POWERCON.2010.5666688

[19] Pongratananukul, N. and Kasparis, T. (2004) Tool for Automated Simulation of Solar Arrays Using General-Purpose Simulators. IEEE Workshop on Computers in Power Electronics, Urbana, 15-18 August 2004, 10-14.

[20] Hyvarinen, J. and Karila, J. (2003) New Analysis Method for Crystalline Silicon Cells. 3rd World Conference on Photovoltaic Energy Conversion, Osaka, 11-18 May 2003, 1521-1524. https://doi.org/10.1016/S1473-8325(03)00623-0

[21] Kensuke, N., Nobuhiro, S., Yukiharu, U. and Takashi, F. (2007) Analysis of Multicrystalline Silicon Solar Cells by Modified 3-Diode Equivalent Circuit Model Taking Leakage Current through Periphery into Consideration. Solar Energy Material and Solar Cell, 91, 1222-1227. https://doi.org/10.1016/j.solmat.2007.04.009

[22] Carrero, C., Amador, J. and Arnaltes, S. (2007) A Single Procedure for Helping PV Designers to Select Silicon PV Module and Evaluate the Loss Resistances. Renewable Energy, 32, 2579-2589. https://doi.org/10.1016/j.renene.2007.01.001

[23] Chin (2011) Fuzzy Logic Based MPPT for Photovoltaic Modules Influenced by Solar Irradiation and Cell Temperature. 13th International UkSim Conference on Modelling and Simulation, Cambridge, 30 March-1 April 2011, 376-381. https://doi.org/10.1109/UKSIM.2011.78

[24] Azzouzi, M., Popescu, D. and Bouchahdane, M. (2016) Modeling of Electrical Characteristics of Photovoltaic Cell Considering Single-Diode Model. Journal of Clean Energy Technologies, 4, 414-420. https://doi.org/10.18178/JOCET.2016.4.6.323

[25] Rodrigues, E., Melício, R., Mendes, V. and Catalão, J. (2011) Simulation of a Solar Cell Considering Single-Diode Equivalent Circuit Model. Renewable Energies and Power Quality Journal, 1, 369-373. https://doi.org/10.24084/repqj09.339

[26] Hansen, A.D., Sorensen, P.E., Hansen, L.H. and Bindner, H.W. (2001) Models for a Stand-Alone PV System. Forskningscenter Risoe. Risoe-R, No. 1219.

[27] Hatziargyriou, N., Kariniotakis, G., Jenkins, N., Peças Lopes, J. and Oyarzabal, J. (2004) Modelling of MicroSources for Security Studies. CIGRE, Paris, 29 August-3 September 2004.

[28] Benavides, N.D. and Chapman, P.L. (2008) Modeling the Effect of Voltage Ripple on the Power Output of Photovoltaic Modules. IEEE Transactions on Industrial Electronics, 55, 2638-2643. https://doi.org/10.1109/TIE.2008.921442

[29] Benamara, V. (2012) Etude et simulation d'un panneau solaire raccordé au réseau avec périphérique de stockage.

[30] Hosseini, H., Farsadi, M., Lak, A., Ghahramani, H. and Razmjooy, N. (2012) A Novel Method Using Imperialist Competitive Algorithm (ICA) for Controlling Pitch Angle in Hybrid Wind and PV Array Energy Production System. International Journal on Technical and Physical Problems of Engineering, 4, 145-152.

[31] De Soto, W., Klein, S.A. and Beckman, W.A. (2006) Improvement and Validation of a Model for Photovoltaic Array Performance. Solar Energy, 80, 78-88. https://doi.org/10.1016/j.solener.2005.06.010

[32] Ahmad, G.E., Hussein, H.M.S. and El-Ghetany, H.H. (2003) Theoretical Analysis and Experimental Verification of PV Modules. Renewable Energy, 28, 1159-1168. https://doi.org/10.1016/S0960-1481(02)00228-8 
[33] Vivallva, M. (2009) Modeling and Circuit-Based Simulation of Photovoltaic Arrays. 10 th Brazilian Power Electronics Conference (COBEP), Bonito-Mato Grosso do Sul, 27 September-1 October 2009, 1244-1254. https://doi.org/10.1109/COBEP.2009.5347680

[34] Hussein, A. (2017) A Simple Approach to Extract the Unknown Parameters of PV Modules. Turkish Journal of Electrical Engineering \& Computer Sciences, 25, 4431-4444. https://doi.org/10.3906/elk-1703-14

[35] Tayyan, A. (2013) A Simple Method to Extract the Parameters of the Single-Diode Model of a PV System. Turkish Journal of Physics, 37, 121-131.

[36] Hadj Arab, A.C.F. and Benghanem, M. (2004) Loss-of-Load Probability of Photovoltaic Water Pumping Systems. Solar Energy, 76, 713-723.

https://doi.org/10.1016/j.solener.2004.01.006 